\title{
Criteria of Selecting and Purchasing of the It Security Solutions, Used By Retail Companies
}

\author{
Filip ILIE \\ Department of Machine Elements and Tribology \\ Polytechnic University of Bucharest. ROMANIA
}

\begin{abstract}
Purchasing behavior of organizations differs from that those of persons. Buying behavior of organizations is the result of decisions, responsible makers within organizations, regarding the purchase of goods and services. Motivation is generally rational, it establish the products and services that will be purchased only on based the technical characteristics of their and not on "sympathy"of the persons in charge of procurement. To purchase products/services at the beginning of each year or semester are set budgets for each department. In case the IT department, at the beginning of year, is established the products/services they will need and a ceiling - overall - on which they can not overcome. Both public institutions and large companies when it comes to a certain value of products they want to buy them, using as the purchase method, the auction. The base of auction is represented by the tender specifications. In it are listed all of the products/services characteristics, so in order to fully satisfy the need of organization/company. The aims of this paper is to find the criteria for the selection and purchase of IT security solutions, used by retail companies and presenting of IT security solutions, on market in Romania.
\end{abstract}

Keywords: IT security solutions, retail companies, purchasing behavior of organizations, decision and the behavior of the collective consumer.

\section{INTRODUCTION}

In the contemporary world, the satisfaction of needs represents reason of economic activity, it is the result of consumption achieved by each person, family or the wider population. Consumer behavior has been, is and will always be subject to ongoing concerns of modern firms.

Current companies were those that were able to focus on customer needs and to give the feeling of a continue desire to satisfaction of the needs, needs and motivations that are ranked best in Maslow's pyramid. On the basis of this pyramid consists of 5 steps in dependency relationship, the companies have developed the products and services. These steps are: elementary biological needs (physiological: satisfaction needs sleep, breathing, water, food, warmth, shelter, move); the need for security, protection (house, clothes, tools, safety in case of dangers); social needs, of belonging to a group; the need for individualization, to esteem and need for self-achievement: the fulfillment of dreams and propouse goals, succeed in life.

Currently, the modern consumer does not follows this hierarchy, but the needs hierarchy, in function by motivations and emphasized needs of the society in which he lives.

The presence of competition, from increasingly strong on market, requires the need knowledge of consumer behavior to preserve and ensure the economic market position, but and in order 
extending and increase market share. Consumer behavior is a component of the economic behavior of people, which in turn represent a form manifestation of human behavior in general [1 - 3]. In modern marketing, consumer behavior assumes the entire conduct of the end user of materials and un-materials goods, including, for example, and voter behavior, patients or even of the parishioners. Consumer behavior can be defined in a specific approach as a multidimensional concept, as a specific resultant of a system of dynamic relationships between the processes of perception, information, attitude, motivation and the effective manifestation, which characterizes integration of the individual or group in space described of all consumer goods and services, existent in society at a time, by individual decisional acts and group to the these. In other words, consumer behavior includes and the concepts of:

- Behavior of buy

- Behavior of consumer.

Between these two concepts and consumer behavior exists relations from whole to part, the most comprehensive concept being "consumer behavior" (purchase behavior). The fact that the act of purchase is understood not simply as a reaction between income and price or between income and expenditure, must be determined all dimensions leading to manifestation a certain consumer behavior. Among these, the most important are: the reasons of buy or unbuy of goods and services, customer preferences, purchase intentions, buying habits, drinking habits, attitudes, image $[4,5]$.

The desire to better understand consumer behavior has led to numerous scientific research. Thus, scientists have tried to explain and describe consumer behavior in terms of mechanisms and processes that operate in the "black box". Therefore, have appeared a series of fundamental theories and global models made in light of several scientific disciplines.

Marshallian model supports the theory that buying decisions, and the real purchase of goods and/or services are the effect of rational calculations and aware economic made by consumers. People spend their income, buying those products that offer the greatest satisfaction, consistent with rational tastes and with the prices they have to pay. This method examines the modification effect a single variable, namely, the price.

Pavlovian model is a model of consumer behavior that is based on learning theory. This model operates with four basic concepts: momentum, suggestion, reaction and relapse. Impulses are needs, motives, aspirations, preferences, etc. of strong stimuli associates' individual's that it forces on this, at the action. Impulses can be: primary (hunger, thirst, cold) and acquired (learned) in social relations (cooperation, fear).

Freudian model, has at based the explanation of consumer's behavior in function the biological and cultural elements. The model puts the focus on the motivational research of customer behavior, of its attitude.

Veblenian model sustain supports the need of complement and deepen of motivational research on consumer behavior with study of social influence exerted on its. According to this model, the levels at which society influences consumer behavior are: culture (values, traditions), subculture, social classes, reference groups and groups belonging.

Hobbesian model brings up the question of consumer behavior associated with people who represent organizations. This model highlights the purchase of goods and services for institutionalized collective entity. And if this type of consumers is put problem taking of purchasing decisions, on goods or services, specification of such decisions is marked by type of 
organization. In some organizations, such decisions are taken by persons, special designated, and others - of various collective management (executive offices, boards of directors, collectives of leadership).

This model is characterized by the presence of two different views:

- Preponderance of rational reasons related to the interests of the organization (theoreticaly, people that make decisions should put on the forefront what is useful for the organization, which does not always happen)

○ Preponderance of personal reasons.

CONSUMER'S DECISION ON THE PRODUCT OR SERVICE CHOSEN FOR PURCHASE

The decision is the result of a process - decisional process to purchase a product or service. This process consists of the following phases:

\section{A) Emergence of Unmet Need}

Consumer feels when there is a perceptible difference, large enough, between ways how is satisfying a particular need, and way how he would like to be satisfied.

A situation which leads to emergence of one unmet need may consist and in technological progress. Expanding the use of electronic computers and robotics have led to the emergence of new needs or services, such as for example: the need for security products and services.

\section{B) Seeking Information and Identify Alternatives}

The information are necessary consumer to identify and assess available alternatives in order to substantiate the decision to purchase. Depending on the nature of product / service or of consumer characteristics, will vary the amount and kinds of information.

For example, security products and services whose value is relatively high and with a lower frequency of purchase, information requested, will tends to have a larger volume, and its sources are diverse. Information sought of consumer, targeting issues, such as:

- The various existing alternatives in terms of products and services considered;

- Their attributes (features corporal and acorporal, technical, economic or otherwise);

- Advantages and disadvantages of the various alternatives identified;

○ Possibilities of obtaining.

The consumer may use an internal search or an external search. Sources of an external searches for information may consist of: experience of consumer, his personal sources (relatives, family, friends, acquaintances); maketing sources (advertising, sales promotion, free advertising) and other sources (press and various publications).

\section{C) Mental Evaluation of Alternatives}

Once consumer get the necessary information, it will filter through the structure of its values and beliefs. The extent and degree of coverage of the evaluation process are influenced by the following factors:

○ The consumer experience;

- The importance of product / service considered;

- The cost of making an incorrect decision;

- Complexity of the alternatives evaluated;

$\circ$ The urgency of taking the decision; 
Result of searches consumer is represented by the "set of alternatives evoked", consisting of a relatively small number of alternatives/options, subject evocation. The evaluation process consists of three aspects:

- Identification of criteria (attributes) on that the consumer uses in evaluating and comparing alternatives considered. Criteria/attributes used by consumers in evaluating alternatives considered are determined by the nature and the specific of goods and services;

- Structure of beliefs and values associated with consumer;

$\circ$ Using decision rules (heuristic rules).

\section{D) Results Evaluation}

This step takes into account the consumer's decision on the purchase decisional process in which is employee with the possibility:

○ To buy the product/service;

○ Do not buy the product/service;

- To postpone the purchase;

$\circ$ Replacing buying the initial of another product.

\section{E) Post-Purchase Evaluation}

To the extent that the consumer has some reasons dissatisfaction, appears as its unrest known as cognitive dissonance. This is all the greater as the value of the product is higher.

Criteria that are used by consumers in choosing the goods and services are:

- The consumer's income (if income increases then and the demand for goods will be higher);

- The needs of the consumer (with how are greater the needs, with both demand for goods will be higher);

- Tstes and preferences;

- Tradition and fashion trends

- Trademarks and logos (with how mark at goods is the most famous, with both in the demand for goods will be higher);

$\circ$ Quality (if the quality is very good, then and the demand will be high).

- The criteria can be:

O Objectives: price, features, physical characteristics of the product;

- Subjectives: determined by intangible factors.

\section{COLLECTIVE CONSUMER PURCHASING BEHAVIOR}

Field of collective consumers (companies, governmental organizations, political) enjoys a presentation less extensive in specialized literature, although its significance is of the decisive importance for development appropriate of the functions leadership of collective consumers. Although there are some common elements of the economic behavior of individual and of collective consumers, that allow the achievement of analogies, its specific elements, it outlines in a separate field of research.

Purchase behavior of collective consumers is the result of decisions of factors responsible within organizations, regarding the purchase of goods and services.

The manifestation of collective consumer's behavior still remains the market. Scrolling this process, in terms of content, period, duration, participants and completion methods etc. is based on a deeply rational motivation, without completely exclude the intervention of affective stimuli, associates of persons involved. The specific of function of purchasing collective 
consumers and the multitude of situations in which this is achieved, impose the makers a suite of skills:

1. Technical competence - given of thorough knowledge of all quality parameters of goods/services that are traded;

2. Economic competence - reflected in knowledge about the characteristics of the market on that works, the current situation of its, the system of prices and pricing, trading conditions offered by potential suppliers;

3. Legal competence - sound knowledge of domestic economic legislation, of international trade law, and about the common practices, customs, habits, etc. from areas that may come trading partners;

4. Financial competence - reflected of mastered of domestic and international financial mechanism and of the credit for production, investment or consumption.

American authors Webster and Wind [6] called the decision-making unit on the buying of products/services within a company organization - "purchase center".

After the way they are involved in the complex process of negotiation and purchase, collective consumers are structured in the following way:

a) Users - representatives of those who will use the goods / services purchased;

b) Influencers - those who through their specialized training, such as to ensure comprehensive evaluation of the quality of supply, directly influence the purchasing decision;

c) Purchasers - those with direct responsibilities in formulating option for a particular vendor and concluding purchase contracts;

d) Decision makers-those who have the word decisive in final option for a particular supplier;

e) "Guards" - those who have a controlling role on the assembly of information underlying the decision to purchase a product/service.

On organizational market, buyers are "professionals". In general, buyers of industrial products are represented by specialists with highly qualified, good knowledge of products, knowledgeable about everything there is on the market in this area, being able to discern between the different versions available on the basis of norms (product specifications) prestable.

The decision to purchase is longer requiring besides to the analysis of technological parameters and certain efficiency calculations. These take into account not only the product, but delivery times, methods of installation and integration in the technological flow, pricing, complementary services etc. Negotiations for concluding contracts are longer than at the individual consumer goods, these having as their main objective, the harmonization of partners' economic interests (embodied in contracting clauses, detailed and precise). The whole decisional process is the result of teamwork of components the so-called "purchasing center" of the company. The demand for the productive goods is determined by the production of consumer goods, so we can say that it is a request "derived".

There are the following type's purchases of collective consumers:

New purchase - the company is in this position when she first buys a certain product. 
Repeat purchase - if the purchasing process is repeated on the same bases as before now, maintaining, of rule, exactly in the same conditions as and in the previous acquisition relationships.

Repeated acquisition changed - the situation is characterized by a modification of the way in which were carried out the previous acquisition relationships (modification of contractual elements, such as quantity, price, delivery terms).

Decision criteria used to purchase of productive goods, are:

Product availability. Products must exist in the offer to potential suppliers in the desired quantity and at desired time.

Product quality, must be consistent with the specifications that the company desires them, otherwise, it will not can achieves the proposed performances (products, at a certain quality and at a certain price).

The optimal price paid for quality and availability of product.

Additional services that accompany the product. The company desires to obtain not only a single product addressed of one certain need, but a "solution" integrated, that to satisfies several objectives.

Long-term relationships - the duration of economic relations on that sets them the company, is desires to be larger.

Stages of process of industrial purchase are:

- The emergence and identification of a certain need;

- The establishing of quantity, quality and terms of delivery;

- Define the products characteristics to be purchased to meet the need or identified needs (preparing product specifications);

- Identification of likely suppliers to meet company requirements;

- The launch of the tender;

- Receiving and analyzing various offers and preliminary negotiation with the suppliers from which they have been received relevant offers;

- Choice of provider or providers with that are to hold talks to conclude contracts;

$\circ$ Evaluating the effectiveness of relationships with suppliers.

\section{SOLUTIONS MARKET IT SECURITY IN ROMANIA}

In 2011 it was stated that the IT market will grow in 2012 in Central and Eastern Europe with approximately 8-15\% especially in countries like Romania, Poland, Bulgaria and Croatia. These statements were made once with the study published by analyst's Austrian group Erste Group, which investigated IT market from CEE with one major growth potential in the coming years (Figure1). These perspectives are due to increased interest for mobile technologies and cloud computing, but in the same time took into account the impact they can have European funding grants. According to analyzes conducted, the increases were expected at the IT market level, to $12.7 \%$ in Romania, to $7.8 \%$ in Poland, $15 \%$ in Bulgaria and $10.1 \%$ in Croatia.

Analysts felt that the factors that will influence the growth allocated budgets of IT, will be those related to reducing costs, operational efficiency amplification, of the need to increase labor mobility, and flexibility of IT systems [7]. It was considered that the wave of purchases will be determined by fundamental factors such as funds structural, public projects (necessary 
legislative harmonization and EU accession) and the technological nature factors that are current trends, present in throughout the IT industry: cloud computing and oriented on IT service, new-generation communication networks, and mobility.

Despite this study by the end of 2011, things turned out to be the exact opposite, Romania being in 2012 on the verge of a steep market declines by software and IT services, because of economic factors, political, but also because of companies education, in the use of information technology, and the lack of information and awareness that, these softwares and IT services are almost indispensable to any company.

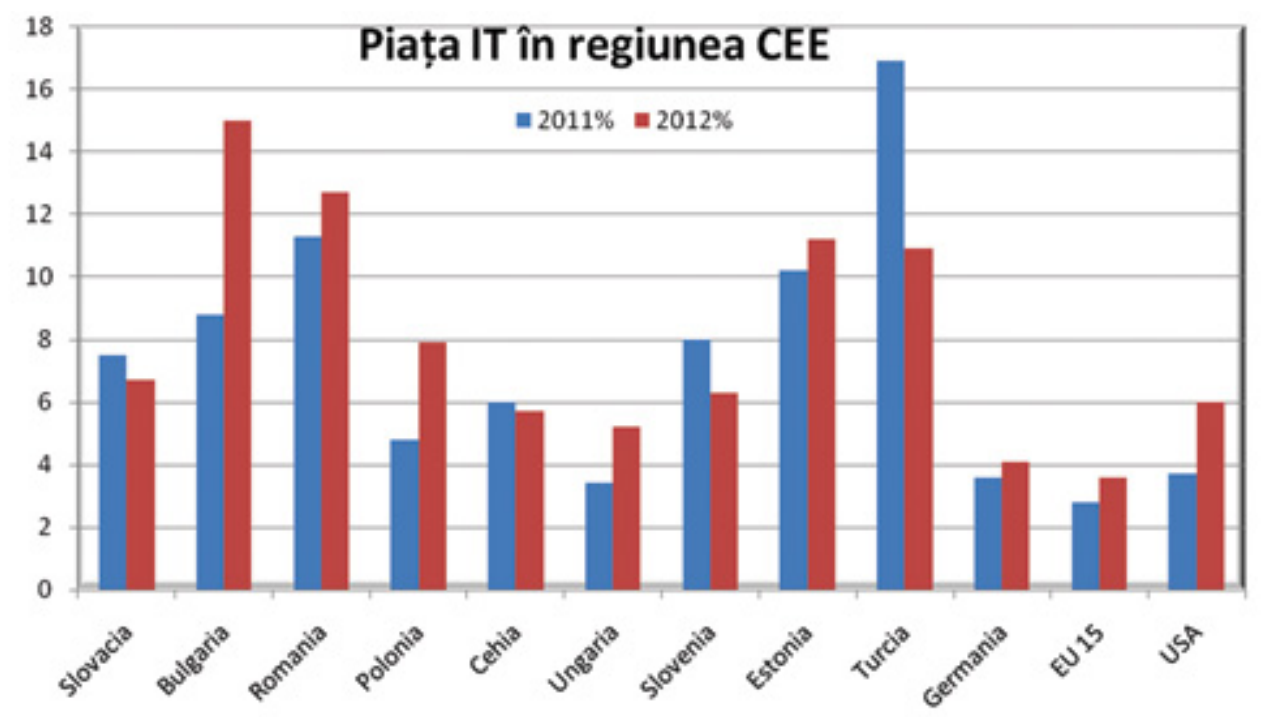

Figure 1 Evolution of the IT market in the CEE region Source: "Market Watch" [8]

According to consulting company - Pierre Audoin Consultants (PAC) for Eastern Europe, [9] were realistic declines of $15-20 \%$ in revenue from this segment, thus representing a decline of $7-10 \%$ for the IT market in Romania.

The factors that could have caused an increase in the IT market are:

- Cloud computing - assumes the accessing of an IT system such as: applications, platforms, and infrastructure; as a monthly subscription, without requiring large investment, such as: licenses, equipment, consulting services and security auditing. This domain is attractive in particularly for many companies in the SMB (Server Message Block) category due to lack of capital;

- Mobility, and new-generation communication networks - implies the possibility of employees working outside the office. Awareness of the benefits made of mobility, have led to increased sales of smartphones and tablets in most markets. Official figures show that in 2011 the mobile telephony, mobility is $82 \%$ and the mobile data are growing exponentially ( $26 \%$ of sales were smartphones);

- The need of efficiency and operational cost reduction - in the economic crisis many companies have had to develop necessary tools to effectively manage an activity not very well optimized. Thus, have was imposed implementation of management solutions required to provide truly relevant information in real time and assist in decision making;

\section{- European funds for public projects.}


Situation that blocked the new projects and initiatives regarding rapid adoption of IT solutions in public and central administration, was the political, she being the one that to hampered the whole process of making decisions regarding the signing of IT projects. Corporate sector which generates in Romania better than half the sales of software, services and IT equipment is the public sector, followed by the one private (banks and telecom companies).

Despite these steep declines of software market and IT services, "vendors will put in value the whole arsenal to gain ground," say Research Analysts, IDC Romania [10, 11]. "Support services and system integration will continue to dominate IT services market, and project type contracts will become increasingly more widespread over the year. This will encourage competition, because project type contracts with a clear deadline set means that beneficiaries can migrate from one provider to another, more easily than in the case of long-term service contracts" $[10,11]$.

Software market, the competition will also be very strong. As a country recently become EU member, Romania is presented as an attractive market for software vendors across Europe as well as for multinational companies interested in new opportunities. According to IDC, local vendors with powerful and effective strategies for development will suffer.

Romanian market of products / security solutions we have the following structure:

1. Manufacturers of security solutions (most of them are foreigners);

2. Distributors - Romanian companies which markets these products resellers;

3. Resellers - companies that sell products / services to end users (consumers individual or collective).

Producers number of products/security solution is quite large, but the most important are: Check Point, Juniper Networks, IBM, McAfee, Bluecoat, HP, Cisco, Aladdin, Application Security, DigitalPersona, Guidance Software, Imperva, Imprivata, Vmware , Hitachi, Websense, BitDefender, etc.

\section{Classification and characteristics of security solutions}

A classification of security solutions might be the following:

\section{a) Biometric Solutions (Biometrics)}

Explosion of phenomenon "cybercrime" to stimulated the spread of biometric security systems. Today, the use of biometric methods - Identification and authentication methods based on individual physical characteristics such as fingerprints, voice, face shape, iris, retina, hand geometry, etc. has become not a reality but a necessity.

Biometric technologies are already preferred solutions of a wide area of applications and, in particular, in domain of access applications, there where the accuracy of identification or verification of an individual is crucial to security. This technology is becoming more easily integrated into the security systems of organizations and significantly more accurate compared to current methods of identification - the password or PIN.

An access system, based on cards can impose a certain degree of control, but cannot make the connection between the card and the person, this can be lost, borrowed or reproduced. Systems using PINs (personal identification numbers) provide that a single individual knows the specific code, that authorizes access, but not in this case cannot make a connection between 
the person entering the PIN and who is the "owner" of access code. By achieving of the connection between the individual and action, biometric technology eliminates all these disadvantages, preventing the intrusions or the unauthorized person's access, thus eliminating possible frauds in the system. It is expected that in this century, the biometry, to be incorporates into national security solutions, leading immediately to improved airports security, the migrations control and verification of identification documents or of visas, and not least in preventing theft identity.

In so-called biometrics industry, exist clear distinction between the terms "identification", "recognition" and "verification". Identification and recognition are essentially synonymous terms, and in both processes (who are called "one-to-many comparison"), a sample represented by an individual characteristic is presented of the biometric system. This tries to determine, by comparison it with those in the database, whom belongs the sample. Thus, during the identification process, the biometric system answers the question: "Who is the person?" and establishes if biometric sample processed exist or not in its database. Verification is practically a "comparison one-to-one", in that the biometric system uses a new sample to a comparison it with previously stored patterns. In this case, if ones the two samples is fit, the system confirms the identity of the individual, answering the question: "Is the individual who claims to be?" What happens if desired, for example, identification a terrorist who is embarking into an airplane?

Identification method, has not in this case, a very high efficiency. On one hand, existing databases do not contain data of all terrorists, and on the other hand the high rate of false alarms determine, over time, a reduction of operator's vigilance, due to their habit with the alarms. All you have done is to be identity checked proves to be more effective. All you have to do is to be checked recognizable identity person with the information stored in databases.

The first step that an organization has to do in choosing biometrics, as solution of identification of personnel, is the evaluation of internal security needs. Must be considered: security level optimum, solution accuracy, costs and implementation time, and the impact on personnel. From the point of view of the security level, of biometric identification techniques of the physical characteristics of the individual are much more accurately, offering, therefore, a more high security level. In terms of accuracy, retinal scanning and iris identification are biometric methods very accurate, but both are extremely expensive and is addresses only the organizations with a highly advanced security level.

Techniques for the identification and recognition based on fingerprint, the facial scan or hand geometry provides a good accuracy at a more affordable price. Costs and time of implementation of a biometric system can be determined by analysis of factors that include: time for research, acquisition of solution, installation of hardware devices of capture and of software afferent, that managing the necessary databases of authentication, integration time of system in organization, personnel training and familiarization to all users with new identification method. The impact of biometric system on personnel is a very important issue. In this regard, employees must to be adapt to all requirements of the system, before as it to be implemented. There are more many companies offering such a product / solution:

○ DigitalPersona - http://www.digitalpersona.com/;

o Privaris - http://www.privaris.com/;

- Suprema - http://www.supremainc.com/;

- Precise Biometrics - http://www.precisebiometrics.com/;

○ Rsa Security - http://www.rsa.com/ etc. 


\section{b) Data Security}

"Data security" is a method of protecting information against foreign access. One method that helps ensure privacy through controlled access to information is found in [12].

There are the following solutions that can achieve data security:

1. Content Monitoring and Filtering;

2. Database Activity Monitoring;

3. Encryption Software;

4. Electronic and Digital Signatures;

5. Public Key;

6. Network Behavior Analysis.

Content filtering is a technique whereby content is blocked or accepted. It is based on its analysis and not on source or other criterion. It is most used for internet to filtering of email or of web content. Filtering of email is commonly used as a method for filtering spam. Acting either on information included in the email body, either on the subject, to classify, accept or reject the message.

Content filtering is used by organizations - schools or offices - to prevent accessing sites and view their pages by computer users. Filtration rules are usually set by the IT department, and can be implemented at each computer through of programs or can be put in networked, in a point which could be either "proxy server" or the Internet router. Depending on how complex is the system use, is can that users of the various computers to have different levels of access to the internet. This security solution is often used on home computers to restrict children's access to inappropriate sites.

Database security is a system, a set of processes and procedures that protect a database, from an undesired activity. This can be characterized as an abuse authorized, as malicious attacks or inadvertent mistakes (careless) made by authorized person or by different processes.

Traditionally databases have been protected by an external access through your firewall or of routers from the network perimeter. Due to the database, the information can be protected on many levels and through various methods:

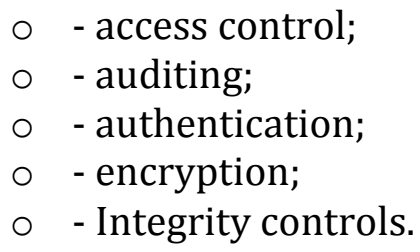

Securing databases can start with the creation process and publication of standards related database security. These standards may include specific commands for the most relevant platforms of database and a set of "best practices", applicable platforms; connections between standards and government regulations.

One important procedure, in evaluation the database security, is to evaluate the vulnerability, to find gaps by which it can penetrate into the database.

Encryption software is a program that focuses on encryption and decryption of the information under the form of files included in the message - mail or the packages sent via Internet. Content security solutions provide protection proactive on levels, which:

1) Optimize the company's communication and network resources due to uncontrolled spam and file transfer;

2) Increase user productivity by controlling of web filtering, of e-mail; 
3) Eliminate the threats: P2P programs, spyware, Trojan type programs, and viruses, for a secure network.

Companies that offer the solutions mentioned, are:

○ Websense - http://www.websense.com/global/en/ (web filtering);

○ ISS - IMB - http://www.iss.net/ (email filter; web filter);

○ McAfee - http://www.mcafee.com/us/ (Anti-Spam / Anti -Spyware Solutions);

○ Aladdin - http://www.aladdin.com (Application filtering; Anti-Spam; Email Filtering; Web filtering; Encription - eToken \& PKI Solutions);

O Imperva - http://www.imperva.com (database security).

- Antivirus Software:

- Intrusion Detection Software (Intrusion Detection Solutions)

Antivirus software is a program that attempts to identify, neutralize or eliminate malicious softwares. Designed in exclusively to combat computers viruses, currently most antivirus solutions are designed to remove a wide range of threats, including "worms" attacks type "phishing" attacks type Trojan and others.

Antivirus uses two different techniques for protecting systems:

1. Examining (scanning) files looking for known viruses included in a list

2. Identify suspicious behaviors of various programs that can infect your computer. Such analysis may include the capture of information and other means

The vast majority of antivirus solutions using both approaches, with a greater emphasis on technique using detection of virus signatures.

An intrusion detection system (IDS) (intrusion detection) in generally detects an unwanted manipulation of the computer (system) in mainly through the Internet. The system is used to detect various malicious events that can compromise the security and trust of a computer system. This includes network attacks on network, of services vulnerable, unauthorized access in network, of the confidential documents, malicious (viruses, Trojan type programs and worms). An IDS is composed of several components:

- Sensors that generate events (security events);

- A console to monitor events and control sensors;

- A central engine that records events, being connected to the sensors in a database that uses a set of rules to generate alerts based on events received ("security events"). There are many companies offering this solutions, such:

- McAfee - http://www.mcafee.com/us/ (antivirus);

○ Symantec - http://www.symantec.com/index.jsp (antivirus);

- Softwin (Bitdefender) - http://www.softwin.ro/ (antivirus);

○ Check Point - http://www.checkpoint.com (IDS);

○ ISS - http://www.iss.net (IDS);

○ Juniper Networks - http://www.juniper.net (IDS).

\section{d) Identity and Access Management (Identitatea și Managementul acesului), includes:}

- Extranet Access Management (EAM);

- Network Access Control (NAC);

- Single Sign-On (SSO);

$\circ$ User Provisioning (UP). 
Of these, important presents:

NAC is a computer security method, that unifies technology of data security from computer (endpoint) (such as antivirus, intrusion prevention at the "host" and vulnerability evaluation), user authentication or of system, with the network security constraint.

SSO is a method of access control that allows the user to identify single once and gain access to the resources of multiple systems by software. "Single sign-off" is the reverse process whereby a single action of renunciation, closing the access to multiple systems.

In a homogeneous IT infrastructure or where there is a single user authentication scheme, or where is a centralized database of users, "single sign-on "is a true bonus. All users of this type of infrastructure would have a single set of login credentials - ie an organization that has / uses an information storage using Lightweight Directory Access Protocol (LDAP).

LDAP is a protocol spread, replacing an older standard X500, used protocol for querying and modifying directory services in TCP / IP environment.

Companies that offer the solutions mentioned are:

Imprivata - http://www.imprivata.com (single sign-on).

\section{e) Internet Security Software}

Internet Security Software is security solutions that allow both use and preserve, protect resources and the information on the internet.

In the IT industry, Internet security refers to technologies that ensure that information stored in a computer cannot be read or compromised by unauthorized persons. Most security measures involve data encryption and passwords. Data encryption is a process that consists of transforming information into a form that cannot be deciphered without a mechanism for decoding (decryption).

Internet security professionals should be experts in four areas (aspects):

1. Penetration testing - is a method of evaluating the security of a computer system or of a network, by stimulating of an attack originated from a malicious user, called "cracker" (often used incorrectly named - hacker). The process includes an active analysis of system to the determining (discovery) of potential vulnerabilities that may result from poor configuration or improper of system, known faults / unknown by hardware or software, or some operational weaknesses in process. This analysis is done from the moment would have created a potential attack, and can involve active exploitation of security vulnerabilities. Whatever security issues that would be presented to the beneficiary of system, with an appreciation of their impact, with a proposal to their 'mitigate' and with a technical solution. The purpose of a "penetration testing" is to determine the feasibility stage of an attack and the impact on business of a great interest to the extent it is found;

\section{Intrusion Detection;}

2. Incidence Response;

3. Legal/Audit Compliance.

\section{f) IT Security Management Software, assumes:}

- Security Information and Event Management.

- Companies provide the solution e) and f) are:

○ IBM - http://www-306.ibm.com/software/tivoli/solutions/security/;

○ ArcSight (HP). 


\section{g) Network Security, includes:}

- Firewall Software;

○ VPN (virtual private network) software.

A firewall is a system or group of systems that imposes a control policy of access between two networks. This gives the network administrator the ability to reject the unwanted or unknown traffic and to them accept, only on the necessary of company or the users, in accordance with [13]. Operation of this varies from one product to another and there are several types:

- Packet filtering firewalls;

o Proxy servers;

- Application gateways;

○ Stateful inspection firewalls.

A firewall is an application or hardware equipment that permanent monitors and filters, the data transmission between PC or local network and the Internet, in order to implement of a "policy" for filtering of access. This policy may be:

- Protecting network resources, by the users rest from other similar networks - Internet $>$ are identified potential "guests" uninvited, their attacks on your PC or of local network, can be stopped;

- Control of resources on that they will access local users.

A VPN - is a network, but not a private one as you would understand from definition, but a network as secure as a private one. If a company has multiple offices in several geographical areas, the traditional solution to connect these offices would be a direct bond, physical, private of company, between them. This model is very expensive and in many cases impossible for realize several reasons. In the help companies that need these networks come in support the VPN technology that encrypts all data and decrypts data that coming through a link. Thus, one can use a public network like the Internet, as a medium of transport for domestic traffic of respective company. Companies that offer solutions mentioned are:

O Check Point - http://www.checkpoint.com (Firewall \& VPN);

○ ISS - http://www.iss.net;

○ Juniper Networks - http://www.juniper.net;

○ Kerio - http://www.kerio.com.

h) Secure Messaging is an approach that is based on the concept of server to protect important information when they are sent outside the company and is offering compliance with international standards: HIPAA, GLBA and SOX. Bring the advantage that confidential and authenticated transfers can be started immediately by any user of the Internet because there is no need to install any software nor prior distribution of a cryptographic keys. "Secure Messages" provides proof that the recipient is identified and transactions are recorded by secure e-mail platform.

\section{i) Vulnerability Management}

\section{j) Wireless Security Software, includes:}

\section{Mobile Data Protection.}

Wireless networks are used both by organizations and individuals. The vast majority of laptops have a wireless card pre-installed. Possibility to can connect to a network then when are moving, you offers many benefits. Also a connection to a wireless network has many security issues. 
Trojan horses - are programs that hide their true purpose or include a hidden functionality on that the user would not want it.

Worms - are characterized by their ability to multiply.

Viruses - are likened to "worms" except that they succeed to multiply by adding their own code on the different software programs.

Once a "worm" or "viruse" infects your computer normally affect / infect other programs (in the case the viruses) and other computers.

\section{CRITERIA FOR SELECTING AND PURCHASING IT SECURITY SOLUTIONS USED BY RETAIL COMPANIES}

\section{The need for security and networking solutions for retail companies}

To be successful in retail distribution should provide customers products and services so that they to return to buy more. However, traders profiling in last 15 years, and especially the steady growth of online shopping has created a buyer's market. To establish and to maintain a competitive advantage in this environment, is a challenge. Given a choice, customers can afford to be more selective, with emphasis on value, services and comfort $[14,15]$. For retail distribution companies, these things make their profitability and development to be very much dependent on the accuracy of the balance between supply and demand, and finding other ways to increase efficiency and control of costs.

A posibility to achieve this objectives is obtaining of a better information. New data and current - for example, corresponding to recent purchasing patterns, the current situation of sales and of the campaigns, the satisfaction and client feedback, stock level etc. - are essential to be able to continue in a good manner all aspects of the supply chain, in accordance with [16]. Among other issues, purchasing, distribution, arrangements and engagement of staffing at each of the stores, must be coordinated much better (wiser). Another way to achieve success is to rely on information technologies and new applications, not just to facilitate the acquisition of information and processing the data mentioned above, but also to increase employee efficiency and for increase knowledge of customer with on services.

A weakness of these two cases in obtain success, is that both is based on an increase of communication level, not only in the store - but, much more importantly, between them and the facilities of the headquarters, and perhaps directly to distribution centers or to other stores. Unfortunately, way to connect of these locations, to allow a bidirectional access to important information / confidential, proves to be inadequate.

In particular, deficiencies performance, security and cost of acquisition occurs because of several factors, including: increasing traffic volumes, the spread of dependence on Internet use, new types of applications and an environment of threats in continually evolving.

For this we need a new solution for the locations scattered throughout the country, of a retail company - a solution that it provides a secure communication in frame and between stores, which providing a protection both for internal and external threats and the same time to touch a new level of cost effectiveness, through consolidation of all productivity requirements of security and of network in a single platform (product - solution). 


\section{Rules and realities of retail distribution}

A closer examination of the trends and challenges that have an impact on the retail business, it's a prerequisite to establish the criterion that best defines an ideal solution of security and the networking for their store and the other stores belonging to the same chain.

In this regard it is important to recognize that retail stores are driven after three fundamental rules: maximizing sales, minimizing costs and reduce risks.

Maximising sales, there are three posibilities in which the company can fulfill this goal.

1. To achieve a consistent as bigger between what sells and what consumers really want to buy (at any time). This approach we lead back to the idea of obtain more information, in many cases directly from the stores.

Analysis of buying patterns, promotional campaigns, demographics structure and so on, can help to ensure that each store have available for sale one optimal of products from portfolio and moreover, that these products are in quantities, brands, sizes, packages appropriate. Significance in this case is the need, frequent change of information between stores and regional infrastructure which is responsible for the collection, analysis and subsequent decisions on procurement and distribution. This can only result in a centralized database at that can access managers and other people, that the informations, them are help.

2. A better understanding of customers, in fact this action is to make consumers aware of the products that the store them has for sale and then to convince them to purchase. In other words it is about promotion. But still, may be and the offering of improved services and thus consumers satisfaction levels, as best. In both cases it is about to build a "store of the future" - a reality today obtained via communication networks and services, that support items as: digital signatures, target and dynamic advertising, promotions, kiosks for self-service and access of public at Internet. From the perspective of implementation of networking and security solutions as beneficial, it put the question of availability, capacity and performance of the connections for network. Also included is the need for segmentation and securing an internal system of networks, in growing.

3. Increased, customer base by increasing geographical coverage - increasing the number of stores in the country. This leads to the need, there is a solution of networking and security, that to be sufficiently flexible, so that it can accommodate different types of Internet services and WAN, different topologies and technologies LAN and facilities for different sizes. Expanding of the solution, for new locations should be quick and easy, requiring little more than a transparent installation of the same platform used by the rest of the locations.

Minimize of cost, there are three ways in which the company can fulfill this goal.

1. Information that helps them increase their sales, may be used and to help control costs. Better information allows retailers to optimize various aspects of the supply chain. The result is reduced costs due to highlight of the source, improving logistics and possibility to work with smaller inventories. The significance of this is, once again, the need to support frequent exchange of information, and of applications from offices.

2. Minimize of IT costs it is no secret that most retail companies have probably dozens of locations that must be maintained / sustained / helped. This implies for an ideal security solution, followings: 
- It is normal for a large volum to have a reasonable unit price. It is impractical to think that organizations are willing to spend tens of thousands of dollars/euros for each store in order to achieve a comprehensive solution for all its location;

- Likewise unpractical is justification of presence of an IT staff at each location. To be considered the security solution must be easy to put on and easy to manage remotely;

- Although most shops are virtually identical in terms, it is inevitable that some of the locations (department stores, distribution centers) it be differ in terms of size, network complexity.

The net result of these factors is that appropriate security solution of the retail locations, besides that must take into account the different facilities of size and need, must be also easy to install and use, especially to remain a solution relatively economic. Therefore, it should be clear that all the applications that are included in one - especially those that have different prices in function of nodes and capacities - are particularly convenient / favorable retail environment. of course, this argument can go, further, to a new phase. We consider we are talking about a complete process, ideal would be that distribution equipments include a complete set of security solutions, but equally and complementary features of networking (eg, routing, WAN connectivity). This, introduce possibility to simplify the infrastructure of a shop, in the same time with the result - "communication solution" (security and networking solution) prevents the need of separate existence of a networking equipment.

3. Investment and use of new information technologies as measure improvements operational efficiency or if not, the reduction of necessary expenses. For example, is can use VoIP to reduce telephone costs, the use of wireless technologies to help sales, the use of "streaming media" and other modern techniques for staff training and the use of RFID technology to assisting management at inventory. These things doubles the importance of an ideal communication solutions for retail. First, the solution provides an additional technologies system that must to be secured, thereby in need of a solution with a sufficient coverage. And then it supports both communication services between stores, and communication services within them.

Reducing the risk, first aspect of minimizing risk is to ensure confidence - this being the availability and performance - in the connections of the networks that belong to of retail stores. Because, organizations develop own communication schemes based on the Internet, becomes, thus necessary the assessement of a security solutions.

\section{CONCLUSIONS}

- Purchasing behavior of organizations differs from that of people through several aspects. Consumer purchase behavior is the result of decisions of factors responsible within organizations, regarding the purchase of goods and services.

- Motivation is generally rational, are established the products and services that will be buying, only on base their technical characteristics and not on "sympathy" of persons dealing with purchase.

- In most cases, buying products/services at the beginning of each year or semester are set budgets for each department. For example the IT department, in early, they set their solutions, by they will need and a ceiling - in total - on which they cannot overcome.

- Both public institutions, and large companies, when it comes to a certain value of products they want to purchase them, using as the purchase method, auction. Auction base is represented by the tender specifications. In this are listed all the products characteristics, such that to fully satisfy the need of the company. 
- The decision to buying of products is taken by the center of acquisition. In particular way, for the purchase of products / IT solutions, we have the following structure of the purchasing center:

1. CSO/CIO - makers;

2. Head of IT - decision maker / purchaser;

3. IT Operation - influencers / users;

4. Audit - influence;

5. Purchasing department - "guards".

The criteria used by each of the members, for purchasing solutions / security products are:

1. CSO/CIO:

Maintaining consumer confidence all confidential information that the company them holds, about either this, or customers are protected and secured. Protection of the investment (equipment meets the company's needs and is a benefit to it).

\section{Head of IT:}

- Protection of confidential data to reduce the risks associated with "negative press" (defamatory articles in the press);

- Wants to avoid non-compliance with the requirements of data security in the company;

$\circ$ Wishes to maintain competitive advantage.

\section{IT Operation:}

- Is interested in product availability;

- Ease of use of the product;

- Interoperability with other equipments in the network;

○ Maximizing employee productivity;

- Minimizing the resources required to put in operation, to manage and to maintain the product/ solution in operation.

4. Audit

- - wants as the security solution it report events in "real-time";

○ - reports to include complete data and conclusive on the events;

○ - Solutions it be in comply with standards type PCI (made by Mastercard).

Based on all these criteria are finalized functional characteristics of the product that the organization wants to them achieve? These features are at specification base. It can be taken by all companies who want to participate in the auction, be free, be in exchange of a guarantee, established by the company.

The criteria that stay typically at the choice base of a solution or other are as follows:

- Services/products to meet the desired characteristics;

- Product availability - the sooner, the better;

- Price, as good. 
Main categories of factors that influence decision making:

\begin{tabular}{|c|c|c|c|}
\hline Environmental factors & Organizţional factors & Interpersonal factors & Individual factors \\
\hline $\begin{array}{l}\text { - Level of primary } \\
\text { demand } \\
\text { - Economic situation } \\
\text { - Purchasing power of the } \\
\text { national currency } \\
\text { - Legislation } \\
\text { - Pace of technology } \\
\text { changes } \\
\text { - Level of competition }\end{array}$ & \begin{tabular}{|l} 
- Objectives \\
- Policies \\
- Procedures \\
- Organizational \\
structure \\
- Systems
\end{tabular} & $\begin{array}{l}\text { - Authority } \\
\text { - Statute } \\
\text {-Empathy } \\
\text { - Power of persuasion }\end{array}$ & \begin{tabular}{|l} 
Personal characteristics: \\
- \\
- \\
- Education \\
- Income \\
- Risk attitudes
\end{tabular} \\
\hline
\end{tabular}

\section{References}

Kotler, Ph. (1997) Marketing Management, Publishing House Teora, Bucharest.

Dumitru, L. (2001) Marketing Basics. House Book's of Science, Cluj-Napoca, pp. 94.

Balaure, V., Adascalitei, V., Balan, C., Boboc, S., Catoiu, I., Oltenu, V., Pop, Al. N. \& Teodorescu, N. (2002) Marketing. Second Edition, Publishing House Uranus, Bucharest.

Cătoiu, I. \& Teodorescu N. (2001). Consumer Behavior. An instrumental approach. Publishing House Uranus, Bucharest.

Cătoiu I. \& Teodorescu, N. (2004) Consumer Behavior. Second Edition, Publishing House Uranus, Bucharest, pp. 21.

Webster, F. C. Jr. \& Wind, Y. (1972) A General Model for Understanding Organizational Buying Behavior. Journal of Marketing, 36, 2, pp. 12-19.

Martínez-Conesa, E.-Á. \& Briones Peñalver, A. J. (2013) Learning Process and Using IT in the Naval Industry, EJKM, 11, 1 , pp. $72-80$.

http://www.marketwatch.ro/articles.php?ai=1587.

Schwab Chesaru E. (Managing Director PAC Eastern Europe) (2012) IT Market in Romania in 2012, whither? Agora TV ep. 15.

Mirea, C. (2008) The local market for IT security. Presentation at Conference IDC IT Security Roadshow 2008.

http://www.comunicatedepresa.ro/idc-romania/.

http://en.wikipedia.org/wiki/Data_security.

http://en.wikipedia.org/wiki/Firewall.

Scarso, E. \& Bolisani, E. (2010) Knowledge-Based Strategies for Knowledge Intensive Business Services: a Multiple Case-study of Computer Service Companies, EJKM, 8, 1,pp.151-160.

Ritala, P., Andreeva, T., Kosonen, M. \& Blomqvist, K. (2011) A Problem Solving Typology of Service Business, EJKM, 8, 1, pp. 37-45

http://www.bursa.ro/on-line/s=companii_afaceri\&articol=23721.html. 